\title{
As Igrejas Protestantes/Evangélicas e o GOLPE CIVIL-MILITAR DE 1964
}

\author{
The Brazilian Protestant/Evangelical Churches
}

AND THE 1964 CIVIL-MILITARY COUP

ZWINGLIO DIAS ${ }^{(*)}$

\begin{abstract}
RESUMO
A relação das igrejas protestantes/evangélicas brasileiras com o Estado de exceção que se estabeleceu no país a partir de 1964, perdurando por 21 anos, foi de adesão das Igrejas do chamado Protestantismo de Missão, na maioria dos casos, ou de passiva aceitação do regime político imposto pelas armas. O texto a seguir procura descrever as causas histórico-teológicas que levaram a esta postura acrítica da grande maioria das igrejas, salientando com exemplos concretos os casos de adesão direta assim como as formas de resistência que se foram formando ao longo do tempo. Ao mesmo tempo procura assinalar os limites impostos por uma leitura literal/fundamentalista do texto bíblico que privatiza as relações do indivíduo com o Sagrado ignorando as dimensões sociopolíticas que tornam sua existência possível.
\end{abstract}

Palavras-chave: Igrejas protestantes/evangélicas brasileiras. Golpe civil-militar de 1964. Dimensões sociopolíticas.

\section{ABSTRACT}

The relationship between the Brazilian protestant/evangelical churches with the military regime established up 1964, and during 21 years, were either one of agreement and support, in the majority of the cases, particularly among the so called Missions Protestantism churches or of passive acceptation of the new political situation. The text try to describe the historicaltheological causes that brought up these churches to this a-critical position showing concrete examples the cases of direct agreement and support and the forms of resistence that were build up along the time. At same time try to sign up the limits of a literal/fundamentalist reading of the biblical text which privatize the relationship between the Holy and the individual not taking in consideration the sociopolitical dimentions that make its life possible.

Keywords: The Brazilian Protestant/evangelical churches. 1964 civil-military coup. Sociopolitical dimentions.

\section{INTRODUÇÃO}
"[...] antes mesmo que as armas e o dinheiro tivessem inaugurado o novo Estado, em 1964, já um processo semelhante acontecia dentro dos espaços pastorais da religião. Neste sentido não se pode negar que as igrejas protestantes tenham sido precursoras do futuro." (Rubem Alves) ${ }^{1}$

Uma das surpresas mais desconcertantes para todo pesquisador atento à história do protestantismo brasileiro, particularmente aquele configurado pelas igrejas nascidas da "Era Missionária" do protestantismo norte-americano, no século XIX, é o fato terrível de nossas igrejas terem se desenvolvido em

\footnotetext{
${ }^{(*)}$ Doutor em Teologia pela Universität Hamburg, Alemanha. Atualmente é professor do Programa de Pósgraduação em Ciências da Religião da Universidade Federal de Juiz de Fora. Tem experiência na área de Teologia, com ênfase em Missiologia, atuando principalmente nos seguintes temas: teologia, política, ecumenismo, direitos humanos, eclesiologia e pentecostalismo. E-mail: zwli@powerline.com.br.
}

${ }^{1}$ ALVES, R. Dogmatismo e Tolerância. S. Paulo: Paulinas, 1982. p. 98. 
contraposição aos reais problemas, condicionamentos culturais e interrogações do conjunto da população do país. Dos primeiros protestantes até nossos dias, depois de mais de um século e meio de presença no interior da cultura brasileira, nota-se um alheamento sistemático, no que-fazer cotidiano de nossas igrejas, dos elementos característicos de nossa história eclesiástica, das marcas culturais que nos identificam enquanto povo e das grandes questões de ordem econômica, social e política responsáveis pela gritante e cruel desigualdade imperante na sociedade brasileira.

Historicamente preso a uma concepção ingênua de sociedade, oriunda de um pietismo hipertrofiado conduzido pela empresa missionária, que não levava em conta as interações entre os grupos sociais e as gritantes contradições de classe, nosso Protestantismo, caracteristicamente, não foi capaz de perceber a natureza peculiar e própria da formação sociocultural brasileira que a distinguia da sua congênere norte-americana. O ideal societário proclamado por meio de sua mensagem teológico-doutrinária não encontrou, por isso, ressonância suficiente que lhe proporcionasse o desempenho de um papel transformador significativo no âmbito sociocultural e político nacional. Contribuiu para isto, e muito, também, sua incapacidade de inculturação, revelada no rechaço de tudo aquilo que constituía, na realidade, o ethos característico da cultura brasileira, mas que era entendido como conteúdo próprio do Catolicismo. Razão porque suas igrejas se caracterizaram, por décadas, como espaços deculturizadores de frações descontentes e frustradas dos incipientes setores médios da sociedade em função de sua impotência social e política. Acrescentese a isto que a proposta eclesiológica, com seu, aparentemente invisível, projeto sociopolítico, dado seu rigorismo ético-moralista, pouco a pouco começará a perder sua capacidade de produção de sentido para os setores médios aos quais, preferencialmente, se dirigia, na medida em que a modernização da sociedade avançava, especialmente a partir dos anos posteriores à II Guerra mundial.

\section{A NATUREZA TEOLÓGICA DE NOSSO PROTESTANTISMO}

Como assinalava o saudoso estudioso de nossa tradição eclesiástica, o Rev. Antonio Gouvêa Mendonça "O nosso Protestantismo é o da era missionária, isto é, do período da expansão dos povos capitalistas, em que a ideologia liberal incentivava o individualismo e o desempenho como instrumentos de ascensão social. O mau desempenho do indivíduo era atribuído ao seu pecado, que nada mais era do que a vida em desacordo com os padrões éticos da cultura capitalista. A salvação consistia na conversão dos indivíduos àqueles padrões, 
isto é, o seu reajustamento ao modo de vida da sociedade tida como cristã e, portanto, perfeita. Toda a Bíblia era vista como repetidas histórias de conversões. A noção da relação do povo de Israel com Deus se perdeu; prevaleceu a ideia da relação de indivíduos com Deus." ${ }^{2}$ Assim, recebendo um modelo eclesial elaborado em outras latitudes, e que respondia às demandas específicas daquela situação histórica particular, as instituições eclesiásticas aqui implantadas se limitaram à reproduzir esse modelo sem se perguntarem se este era, realmente, o mais adequado para as condições socioculturais características da realidade brasileira.

Assim o Protestantismo de Missão no Brasil, segundo uma já recorrente tipologia, foi resultado do investimento missionário das igrejas norteamericanas a partir dos despertamentos religiosos dos séculos XVIII e XIX, principalmente, que deram forma a um protestantismo conservador, antimoderno, por excelência conversionista e muito propenso às teses fundamentalistas. A eclosão desse movimento nos Estados Unidos como que contaminou as sociedades missionárias reforçando o elemento conservador e criando espaços para a admissão, pelo menos dissimulada, das propostas fundamentalistas entre nós. Nas décadas de quarenta e cinquenta, do século passado, a ofensiva fundamentalista, representada pela presença do pastor Carl Mcintyre ${ }^{3}$ visitando as igrejas brasileiras, estabeleceu um divisor de águas bem claro. A maioria das denominações protestantes brasileiras optou por permanecer sem uma definição clara: não aderiu abertamente às teses fundamentalistas, mas tampouco as renegou claramente. A indecisão revelou-se uma opção, pelo menos, latente. As transformações experimentadas pela sociedade brasileira nos anos cinquenta e sessenta que, no mundo eclesiástico protestante podem ser emblematizadas pela "Conferência do Nordeste", realizada em 19624, promovida pela Confederação Evangélica do Brasil, cujo cinquentenário acaba de ser celebrado, e, na sociedade, pelo golpe civil-militar de 1964, se encarregaram de definir a natureza conservadora e, para a maioria dos setores do protestantismo nacional, fundamentalista. As consequências são conhecidas.

\footnotetext{
${ }^{2}$ MENDONÇA, A. Gouvêa. Socialização do Saber Teológico. In: Educação Teológica em Debate. São Paulo/São Leopoldo: ASTE/Sinodal, 1988. p. 17-18.

${ }^{3}$ Ver DIAS, Z. M. Fundamentalismo - O delírio dos Amedrontados. In: Z. Dias (Org.) Os vários rostos do Fundamentalismo. São Leopoldo: Cebi, 2009. p. 19 ss.

${ }^{4}$ Ver ROSA, W. P. da, ADRIANO F ${ }^{\mathrm{o}}$, J. (Orgs). A Conferência do Nordeste 50 anos depois. Rio de Janeiro: MAUAD Ed./Inst. Mysterium, 2012.
} 
Segundo a figura, já clássica, criada pelo teólogo metodista de Sri Lanka, Daniel T. Niles5, em meados do século XX, quando refletia sobre os reveses sofridos na Ásia pela empresa missionária dos cristãos da Europa e da América do Norte, a planta do Evangelho, em sua subespécie protestante não foi retirada, até hoje, do vaso cultural/teológico em que foi transportada para os países periféricos. Foi plantada ali com vaso e tudo, ignorando as condições peculiares do solo histórico-cultural dessas populações. Em nosso caso particular, de protestantes brasileiros, salta aos olhos de qualquer observador acurado que nosso protestantismo, em que pesem os esforços realizados nos últimos cinquenta anos por não poucos grupos em nossas diferentes igrejas, não passa ainda de um epifenômeno que se desenvolveu e continua se desenvolvendo à margem de nossos valores culturais mais legítimos, que continuam sendo negados e demonizados, e ignorando os anseios e necessidades mais profundas de nossa população. Além disso, fazendo coro com interesses que não são, propriamente, os do povo brasileiro que, ainda hoje, continua a transitar, com a alma despedaçada, de comunidade em comunidade, em meio à violência, tanto estrutural como individual, sem uma mensagem sólida que lhe reestruture os sonhos de esperança no futuro e lhe permita descobrir a graça e o sentido profundo da vida.

Um exemplo claro, em nossos dias, dessa religiosidade importada é a chamada cultura Gospel ${ }^{6}$ que, oriunda da mesma matriz, aqui chegou para "modernizar" o envelhecido modelo eclesial que nunca foi capaz de incluir, por exemplo, a riquíssima herança cultural da música brasileira em suas manifestações litúrgico-devocionais. Ou seja, o vaso cultural que transportou as primeiras mudas do Evangelho para o nosso solo nunca foi quebrado e com isso condicionou e determinou o crescimento da planta dando origem a uma subespécie eclesiástica que mais corresponde às propriedades inerentes à composição do vaso, do que àquelas das mudas originalmente ali plantadas. Neste sentido, nossas igrejas tem desenvolvido uma função deculturizadora uma vez que a mensagem que anunciam está marcada pelos condicionamentos culturais e ideológicos da matriz missionária original.

Por outro lado, pelo fato de não desenvolver uma reflexão teológica própria, crítica da herança recebida e crítica, também, das manifestações cultural-

\footnotetext{
${ }^{5}$ NILES, D.T., That they may have Life. Londres: Lutterworth, 1952.

${ }^{6}$ Ver CUNHA, M. Nascimento, A Explosão Gospel. Rio de Janeiro: MAUAD ED./Inst. Mysterium. 2007.
} 
religiosas de nosso próprio contexto histórico, porém assumindo-o como a matéria-prima para a criação de uma expressão eclesial protestante verdadeiramente brasileira, nossas igrejas se encontram hoje à mercê das injunções impostas tanto pela religiosidade tradicional brasileira como pelos “valores" proclamados pelo mercado.. Pouco a pouco vão triunfando em nossas comunidades as manifestações de uma religiosidade utilitarista, profundamente marcada pelo individualismo, pelo "negocismo" com o Sagrado que tem suas origens no velho catolicismo colonial das promessas aos santos padroeiros e na espiritualidade afro-indígena dos "serviços" às entidades espirituais. Formulações que, ao longo da história, foram se aninhando, silenciosamente, no fundo de nosso imaginário coletivo. Tudo isso regado com uma grande dose de histerismo emocional desenfreado, agora identificado e celebrado como encontro com o Sagrado.

\section{O GOLPE MILITAR E A REAÇÃO POSITIVA DAS IGREJAS}

Uma rápida consulta aos periódicos da época, das principais instituições eclesiásticas do protestantismo brasileiro, é mais do que suficiente para demonstrar a adesão destas ao regime político imposto pelas armas a partir de 1964. Editoriais e artigos laudatórios vão preencher as páginas do "Jornal Batista”, do "Brasil Presbiteriano", do "Expositor Cristão" da Igreja Metodista, do "O Estandarte" da Igreja Presbiteriana Independente, do "Mensageiro da Paz" das Assembleias de Deus e de muitas outras publicações de menor porte e alcance no mundo evangélico.

Em um de seus textos analíticos sobre a relação das igrejas evangélicas com o regime militar, o prof. Leonildo S. Campos relata que, quando estava preso na OBAN, (em 1969), recebeu a visita de um pastor batista, capitão do exército, que lhe foi levar um exemplar do Novo Testamento. "Ao ser questionado por um outro preso, se ele não tinha vergonha de torturar presos à noite e levar-lhes literatura evangélica durante o dia nas celas [...] o pastor...afirmou, apontando para uma pistola debaixo do paletó: 'Para os que desejam se converter eu tenho a Palavra de Deus, para quem não quiser há outras alternativas."”7

Questionado, durante entrevista, muitos anos depois, acerca de sua participação no grupo de militares que invadiu os escritórios da Confederação Evangélica do Brasil no Rio de Janeiro, em 1964, um general, presbítero da IPB,

\footnotetext{
${ }^{7}$ CAMPOS, L.S., Protestantes na primeira fase do regime militar brasileiro: atos e retórica da Igreja Presbiteriana Independente (1964-1969). In: Estudos da Religião nº23, UMESP. S.B. do Campo: UMESP, 2002, p. 126.
} 
não só sustentou a legitimidade daquela ação como fez questão de salientar que ele e seus colegas na ocasião não portavam armas já que se tratava de uma organização eclesiástica! ${ }^{2}$

O Prof. João Dias de Araújo em sua histórica pesquisa sobre o envolvimento dos protestantes com o regime autoritário que resultou no livro "Inquisição sem fogueiras" assinala que "entre as igrejas evangélicas do Brasil, a Presbiteriana foi a mais envolvida e a mais comprometida com a revolução de 1964 por causa da ligação dessa igreja com a classe média e por causa do prestígio que gozava nos meios políticos e militares”.

Citando o pastor Jovelino Ramos, o autor continua:” Três presbiterianos da ilustre família Gueiros vem tendo participação ativa no delineamento dos destinos do país desde a deposição do Presidente Goulart. Eraldo Gueiros Leite, no momento em que escrevemos, é Procurador da Justiça Militar, Evandro Gueiros é Procurador da Justiça Cível e Nehemias Gueiros entrou para a história como redator do Ato Institucional $n^{0}{ }_{2}$. Vale mencionar o nome de Jeremias Fontes, outro filho do protestantismo (presbiteriano) designado por Castelo Branco e eleito em pleito indireto para governador do Estado do Rio. No governo Médici, o ministro Eraldo Gueiros ocupou o cargo de Governador de Pernambuco."9

Em sua dissertação de Mestrado sobre “A posição política da IPB nos anos de Chumbo (1965-1985)", defendida na Univ. Federal de Santa Catarina em 2006, Eduardo G. de Moura Paegle relaciona os nomes de quatro oficiais militares de alta patente, originários de diferentes denominações, com funções de importância no seio do regime: cel. Renato Guimarães, presbítero, que na década seguinte se tornou vice-presidente da Igreja Presbiteriana do Brasil, cel. Teodoro de Almeida, cel. Walter Faustini e o major Carlos Alberto Brilhante Ustra, que foi o comandante do DOI de São Paulo ${ }^{10}$. Durante o governo Médici, foi constituída a Assessoria Especial de Relações Públicas da Presidência da República (AERP), um organismo encarregado de coordenar a propaganda do regime militar, que mantinha escritórios em cada Estado. Em São Paulo chefiava essa repartição o Rev. Sérgio Paulo Freddi que além de jornalista era o

\footnotetext{
${ }^{8}$ Relato ouvido pelo autor numa comunidade presbiteriana do Rio de Janeiro.

${ }^{9}$ ARAUJO, J. Dias. Inquisição Sem Fogueiras. 2. Ed. (versão digital). Rio de Janeiro: ISER, 1982. p. 64. Também publicado por Fonte Editorial, São Paulo.

${ }^{10}$ Ver PEAGLE, E.G. de Moura. A posição política da IPB nos Anos de Chumbo (1965-1985).

Dissertação de Mestrado. Univ. Federal de S. Catarina, 2006, p.. 82
} 
pastor do principal templo da Igreja Presbiteriana Independente dessa cidade e um dos redatores da publicação oficial desta igreja, O Estandarte ${ }^{11}$.

Ainda, conforme o prof. Leonildo S. Campos,

foi a partir de 1968, enquanto o clero católico se afastava do regime militar que os evangélicos passaram a dar um apoio ostensivo aos militares. Isso ocorreu tanto com pastores e leigos presbiterianos, presbiterianos independentes, metodistas, batistas, luteranos (em parte) e outros mais. Esse apoio pode ser facilmente rastreado nos jornais evangélicos da época, quer no noticiário como nos editoriais ou na ação de alguns líderes que chegavam a denunciar leigos de suas respectivas comunidades para as forças de segurança. Os pastores aliciados pelo regime cooperaram também participando de cursos da Associação de Diplomados da Escola Superior de Guerra (ADESG) e na ministração de aulas de moral e civismo em colégios públicos e particulares. Alguns evangélicos foram premiados com a indicação para cargos de governadores estaduais. Outros ocupariam altos escalões na administração pública municipal, estadual e federal." ${ }^{12}$

Como expressão do longo conflito geracional que cindia as igrejas evangélicas desde os inícios da década de 1950 forte repressão se abateu sobre os estudantes de teologia das diferentes denominações. Centenas deles foram expulsos dos seminários porque estariam sendo influenciados pela ideologia comunista, assim como expurgos, impiedosos e cruéis, foram perpetrados contra os professores suspeitos de heresia. Estes poucos relatos, que apenas entreabrem as cortinas de um teatro de horrores, já são mais do que suficientes para ilustrar o envolvimento direto de instituições eclesiásticas evangélicas e de muitos de seus eclesianos, individualmente, no apoio aberto ao regime de terror imposto à nação.

\section{OS DIFERENTES MODOS DE RESISTÊNCIA...}

Diferente do universo católico-romano, o mundo do protestantismo, por basear-se na adesão voluntária de indivíduos, supostamente, livres, é profundamente fragmentado. As decisões tomadas e as atitudes assumidas pelos corpos dirigentes das instituições eclesiásticas nem sempre são acolhidas e respeitadas, no todo ou em parte, pelos membros das diferentes comunidades, principalmente quando não se referem diretamente, aos artigos de fé que caracterizam as diferentes famílias confessionais. Com isso, os posicionamentos institucionais em favor do Estado autoritário não foram recebidos passivamente por todos os setores das igrejas. O conflito político-ideológico que cindiu a

\footnotetext{
${ }^{11}$ Ver CAMPOS, L. S. Protestantes..., p. 92/93.

${ }^{12}$ CAMPOS, L. S., ELIANE MOURA DA SILVA, KARINA K. BELLOTI (Orgs.). Religião e Sociedade na América Latina. S. B. do Campo: UMESP, 2010. p. 170.
} 
nação brasileira, a partir da década de cinquenta e que alcançou seu auge com o golpe civil-militar em 1964, também se fez presente no interior das igrejas do protestantismo brasileiro. Muitos protestantes/evangélicos abandonaram suas comunidades de origem por discordarem das posições assumidas por suas lideranças eclesiásticas. Outros trataram de se organizar internamente para, ainda que timidamente, expressarem sua desconformidade. Entre os que foram expulsos de diferentes suas comunidades e considerados hereges por discordarem do alinhamento político de suas instituições, organizaram-se em agremiações tanto de caráter ecumênico como em entidades confessionais alternativas e, mesmo, em pequenas comunidades independentes.

Dois exemplos são marcantes desse processo. Em 1965 é organizado no Rio de Janeiro, por pastores e leigos de diferentes igrejas (presbiterianos metodistas, batistas, congregacionais, anglicanos, entre outros) o Centro Evangélico de Informações (CEI) que, anos depois, se transforma no Centro Ecumênico de Informações (com a inclusão de católicos romanos), o qual vai dar origem, na década seguinte ao Centro Ecumênico de Documentação e Informação (CEDI), que veio a constituir-se numa das primeiras e maiores ONGs do país, com grande expansão na década de oitenta. Com a exclusão das filas da Igreja Presbiteriana do Brasil de várias regiões eclesiásticas inteiras e dezenas de pastores e comunidades locais vai se constituir no final da década de setenta a Federação Nacional de Igrejas Presbiterianas (FENIP) que, mais tarde, se constitui na Igreja Presbiteriana Unida do Brasil (IPU).

\section{A GUISA DE CONCLUSÃO}

Apesar desses esforços de resistência à adesão das instituições protestantes ao Estado autoritário estas persistiram em seu cometido inicial, fechando-se sobre si mesmas e impedindo o desenvolvimento de novas alternativas de ser igreja. A reprodução da visão de mundo estabelecida autoritariamente, o cerceamento da interpretação teológica dos novos tempos vividos pelo país, a demonização do movimento ecumênico e a imposição de uma interpretação bíblica de corte literal/fundamentalista levaram essas igrejas à perda paulatina de sua identidade histórico/teológica lançando-as, especialmente a partir de fins da década de oitenta, à voragem arrebatadora do (neo)pentecostalismo.

\section{REFERÊNCIAS}

ALVES, R. Dogmatismo e Tolerância. S. Paulo: Ed. Paulinas, 1982. 
CAMPOS, L.S. Protestantes na primeira fase do regime militar brasileiro: atos e retórica da Igreja Presbiteriana Independente (1964-1969). In: Estudos da Religião ${ }^{0}{ }_{23}$, UMESP. São Bernado do Campo, SP: UMESP, 2002, p. 126.

ARAUJO, J. Dias. Inquisição sem fogueiras. 2. ed. (versão digital). Rio de Janeiro: ISER, 1982. Também publicado por Fonte Editorial, São Paulo.

PAEGLE, E.G. de Moura. A posição política da IPB nos Anos de Chumbo (19651985). Diss. de Mestrado. Univ. Federal de S. Catarina, 2006.

CAMPOS, L.S.; MOURA DA SILVA Eliane; BELLOTI Karina K. (Orgs). Religião e Sociedade na América Latina. São Bernardo do Campo, SP: UMESP, 2010.

MENDONÇA, A. Gouvêa. Socialização do Saber Teológico. In: Educação Teológica em Debate. São Paulo/São Leopoldo: ASTE/Sinodal, 1988. p. 17-18.

Recebido em 09/05/2014 Aprovado em 26/o6/2014 